Japanese Psychological Research

1900, Vol. 32, No. 3, $137-147$

\title{
A causal attribution model of academic achievement in senior high-school
}

\author{
AKIMICHI OMURA \\ Department of Educational Psychology, Faculty of Education, University of Tokyo, Bunkyo-ku, Tokyo 113 \\ MAS.IHIRO KAMBARA \\ Department of Psychology, Facully of Letters, Teikyo Universitv, Hachioji, Tokyo 192-03 \\ SEIICHIRO TAKETSUNA \\ Department of Educational Pychology, Faculty of Education, Nigata University, Ikarashi, Niigata 950-21
}

\begin{abstract}
The present study aims to evaluate the individual differences of attributions of actual events in educational settings and to investigate the effect of causal attributions in a natural school setting. Study I examined the structure of causal attributions for academic achievement in high school physics. Although usual factors such as effort, ability, mood, luck, and other persons, were extracted, the following points were noteworthy. Effort attribution of memory task was found to be different from effort attribution in general. 'Ability' and 'task difficulty' were found to constitute the same factor. Study II examined the relationships among the following variables: causal attributions made for the first mathematics test, dissatisfaction with the test performance, expectancy for the next test performance, learning behavior after the test, and the achievement of the second test. One hundred and fourteen high school students served as subjects. It was found that those students who attributed their poor performance to lack of effort felt dissatisfaction and studied mathematics more, and consequently showed a better performance on the second test. That is, the present study clearly showed that causal attributions as cognitive variables had some indirect effects on learning behavior and future performance.
\end{abstract}

Key words: causal attributions, learning behavior, test performance, expectancy, dissatisfaction, natural school setting.

Recently, a number of studies stimulated by the theories of Weiner, Frieze, Kukla, Reed, Rest, and Rosenbaum (1971) and Dweck (1975) reported on the effects of individual differences of causal attributions on students' achievement. These studies suggested that causal attributions affect the future achievementseeking behavior, expectancy for future success and future academic achievement.

1 This research was supported by a grant from the Japan Society for Promotion of Science (19841986) and a grant from the Yasuda Life Welfare Foundation (1987). The authors wish to thank Mr. Yukimasa Muraishi and Mr. Yukio Yoshikawa for their cooperation with this research. This paper is a completely revised and expanded version of the report submitted to the Yasuda Life Welfare Foundation.
Many studies have been carried out in the laboratory using very simple tasks rather than in a real-life setting. It is disappointing that only a few studies have reported the effects of causal attributions on expectancy and achievement in real teaching-learning processes.

Most correlational studies which aimed to investigate the effect of attributional styles on achievement in educational situations assessed them by requiring subjects to describe causal attributions of various hypothetical events instead of real events. It is no wonder that causal attributions of hypothetical events might be affected by the past experiences of those events. The present study aimed to evaluate the individual differences of attributions of actual events in educational settings and to 
investigate the effect of causal attributions in a natural school setting.

l'urthermore, a critical issue in attributional research is the validity of hypothetical causal factors. A number of studies traditionally accepted four causal factors: effort, ability, task dificulty and luck, based on two dimensions, stability and locus of causality. Recent studies use causal factors based on Weiner (1979)'s three dimensional model which added controllability to the two dimensions above mentioned. For example, Covington and Omelich (1979), which is one of a few pieces of research done in educational settings, uscd four factors and Aikawa, Mishima, and Matsumoto (1985) adopted eight factors based on the three dimensional model.

However the use of the causal factors of Weiner's model a priori has been criticized from several points of view. First, these commonly accepted factors do not necessarily cover all conceivable and significant factors. Second, as these factors were originally designed in laboratory experiments, they may be irrelevant and meaningless in a real-life setting. Furthermore, the relationship between each causal factor and causal dimensions is not as stable nor as clear as expected. Responding to these criticisms, Weiner (1983) recommended that the names of causal factors be changed so as to be more relevant to the situations in question, and that causal dimensions be estimated directly from each situation studied. Ronis, Hansen, and O'Leary (1983) also encouraged the classification of the various causal factors designed to specific situations by multivariate analysis.

According to Ronis' suggestion we tried an exploratory approach in this study. Various causal descriptions suitable to the examination situation in school were estimated independently and then factor analysis was conducted to find out more basic factors.

Then we aimed to investigate the effect of these basic causal factors on expectancy and achievement. A few models of causal attribution and achievement have been proposed. Higuchi, Kambara, and Ohtsuka (1983) proposed the following causal model: attributional styles $\rightarrow$ perceived control $\rightarrow$ learning behavior $\rightarrow$ academic achievement. In this model, attributional styles are independent variables, but specific causal attributions of academic performance in a real setting may be affected by the performance itself. Weiner, Heckhausen, Meyer, and Cook (1972) has already proposed the following model: consequences $\rightarrow$ causal attribution $\rightarrow$ expectancy/emotion $\rightarrow$ behavior. Integrating and modifying thesc two models, the following causal attribution model of academic achievement was proposed in the present study: performance $\rightarrow$ causal attribution $\rightarrow$ expectancy / affect $\rightarrow$ achievement-seeking behavior (learning behavior) $\rightarrow$ performance. This model is essentially cyclic. None of the previous attributional studies has investigated the whole sequence from performance to the next performance. In this study we aimed to examine this sequential relationship and to confirm this model in a real school setting.

\section{Study I}

In this study we tried to find out the structure of causal attributions for academic achievement in high school physics in real school situations.

It was also expected that causal ascriptions would be changed by the situational conditions, such as problem characteristics. The examination is usually made up of various problems. Performance on some problems would be mainly dependent on student memory and performance of others on student thinking ability. These differences in problems (on task specificities) would affect student causal attributions. In the present study we also tried to examine the effects of task characteristics and the generality of individual differences 
of causal attributions in various tasks.

\section{Wethod}

Subjects and procedures. Subjects were 114 freshmen at a high-school affiliated to a university. When students were given back their examination papers with scores in physics class, they were asked to answer their causal attributions for their performance on four problems selected from the examination papers and their total test performance. Students were given explanations of problem solutions by their teacher and then replied to the causal attribution questionnaire.

Four problems were selected from the examination of physics. Problem 1 was a problem which required that the student explain the meaning of several technical terms. Problem 2 and problem 3 could be solved by the simple application of appropriate formulas. Problem 4 was more difficult to solve than the other problems because it could not be solved by simply using formulas. Furthermore, perceived causes of total test performance were evaluated by subjects.

Measures. Subjects were required to rate the importance of the causal factors of their task performance. In this study eleven factors which seemed plausible in natural school settings were designed exploratorily. Five of them have been commonly used in attribution research on achievement motivation (e.g. Higuchi et al., 1983), and six other concrete factors suitable to an achievement test situation in physics were added considering the concept of "Powerful Others" by Levenson (1974). These causal factors were as follows: (1) I made an effort. (2) I felt fine and was in good physical condition at the test. (3) I have ability. (4) The test problems were easy for me. (5) I was lucky. (6) My teacher taught me well. (7) Other persons (my private instructor, my friends, my brothers and sisters) kindly helped me. (8) I reviewed my lessons well at home. (9) I listened to my teacher carefully. (10) I solved exercise problems in the textbook and reference books well. (11) I studied hard on the day before the examination.

Subjects were asked to rate the importance of these eleven factors for total test performance and performances in the four problems. These factors were rated by the students who felt that they did well or rather well at the test. Students who thought their performance poor or rather poor rated the factors with opposite meanings, such as "I did not make an effort.", "I do not have ability.", and so on. Each factor was rated separately on a five-point Likert-type scale from 1 (not a cause) to 5 (very much a cause).

\section{Result}

Principal factor analysis was performed on responses to 55 items (5 problems $\times 11$ causal factors) and it was found that the difference between sixth eigenvalue and seventh was rather large and six factors could account for $55 \%$ of the total variance. Then six factors were rotated by Varimax method. Rotated factor pattern is shown in Table 1 , and factor loadings greater than .45 were marked.

The first factor had large positive loadings for effort items of all problems except problem 1 and the second, third, fourth, and fifth factors all had large loadings for items which could be clustered from the point of causal factors instead of task characteristics. These results showed that the individual differences of causal attribution were relatively stable through various problems. But the sixth factor which bad large loadings for items concerning student effort (such as 'effort', 'review', 'listening carefully to my teacher', ' exercise') suggested the effect of task characteristics in Problem 1 only. This factor reflected efforts specific to problem 1 .

The items which had large loadings of the second factor were ' ability' and 'task difficulty' for all problems. This factor can be called ability factor. Much at- 
Table 1

Factor analysis of causal attribution ratings (varimax method)

\begin{tabular}{|c|c|c|c|c|c|c|c|}
\hline \multirow{2}{*}{ causal factor } & \multirow{2}{*}{ problem } & \multicolumn{6}{|c|}{ Factor } \\
\hline & & 1 & 11 & III & IV & V & VI \\
\hline \multirow[t]{5}{*}{ effort } & 1 & .28 & -.04 & .11 & -.03 & .10 & $.65^{*}$ \\
\hline & 2 & $.55^{*}$ & -.03 & -.37 & -.11 & .14 & .33 \\
\hline & 3 & $6 t^{*}$ & -.01 & .05 & -.17 & .16 & -.14 \\
\hline & 4 & $.68^{*}$ & .02 & .15 & -.19 & .02 & .03 \\
\hline & test & $.55^{*}$ & -.13 & -.28 & -.13 & -.01 & .24 \\
\hline \multirow{5}{*}{$\begin{array}{l}\text { physical condition/ } \\
\text { mood }\end{array}$} & 1 & .05 & .11 & $.79^{*}$ & -.03 & .22 & -.03 \\
\hline & 2 & .11 & .07 & $.25 *$ & .05 & .27 & .07 \\
\hline & 3 & .13 & .21 & $.55^{*}$ & .25 & .22 & .27 \\
\hline & 4 & .13 & .14 & $.79^{*}$ & .06 & .33 & .12 \\
\hline & test & .00 & .08 & $.86^{*}$ & .11 & .12 & .17 \\
\hline \multirow{5}{*}{ ability } & 1 & -.03 & $.52 *$ & .12 & .17 & .18 & -.02 \\
\hline & 2 & .12 & $.66^{*}$ & .07 & .21 & .21 & -.19 \\
\hline & 3 & .21 & $.59^{*}$ & .05 & .28 & .38 & .07 \\
\hline & 4 & .13 & $.69 *$ & .29 & .29 & .03 & -.09 \\
\hline & test & .09 & $.75^{*}$ & .10 & .19 & -.03 & -.10 \\
\hline \multirow[t]{5}{*}{ task difficulty } & 1 & .00 & .31 & -.34 & -.09 & .09 & -.15 \\
\hline & 2 & -.05 & $.78^{*}$ & .06 & .07 & .03 & .12 \\
\hline & 3 & -.15 & $.58^{*}$ & -.01 & .08 & .19 & .12 \\
\hline & 4 & -.03 & $.73^{*}$ & .10 & -.05 & .08 & .04 \\
\hline & test & -.10 & $.71^{*}$ & -.16 & .00 & .19 & .11 \\
\hline \multirow[t]{5}{*}{ luck } & 1 & .28 & .07 & .01 & $.60^{*}$ & .06 & -.35 \\
\hline & 2 & -.08 & .12 & .34 & $.57^{*}$ & .13 & .11 \\
\hline & 3 & -.07 & .07 & .03 & $.66^{*}$ & .29 & .12 \\
\hline & 4 & -.22 & -.30 & .22 & $.50^{*}$ & .24 & .22 \\
\hline & test & -.11 & -.06 & .28 & $.62^{*}$ & .27 & -.03 \\
\hline \multirow[t]{5}{*}{ teacher } & 1 & -.01 & .23 & .23 & .30 & $.51^{*}$ & -.18 \\
\hline & 2 & .12 & .33 & .15 & $.67^{*}$ & -.09 & -.20 \\
\hline & 3 & -.04 & .24 & -.14 & $.62^{*}$ & -.01 & -.06 \\
\hline & 4 & .00 & .22 & -.09 & $.63^{*}$ & .19 & .06 \\
\hline & test & .06 & .23 & .11 & $.60^{*}$ & .20 & -.35 \\
\hline \multirow[t]{5}{*}{ other persons } & 1 & .12 & .30 & .09 & .09 & $.80^{*}$ & -.02 \\
\hline & 2 & -.06 & .12 & .29 & .17 & $.62^{*}$ & .03 \\
\hline & 3 & -.06 & .18 & .14 & .26 & $.71^{*}$ & .13 \\
\hline & 4 & -.02 & .10 & .15 & .22 & $.75^{*}$ & .17 \\
\hline & test & -.02 & .35 & .24 & .15 & $.72^{*}$ & -.05 \\
\hline \multirow[t]{5}{*}{ review } & 1 & .21 & .04 & .05 & -.02 & .04 & $.74^{*}$ \\
\hline & 2 & $.57^{*}$ & .10 & -.34 & -.11 & .13 & $.47^{*}$ \\
\hline & 3 & $.67^{*}$ & .12 & .09 & -.02 & -.09 & -.05 \\
\hline & 4 & $.72^{*}$ & .12 & .12 & .02 & -.05 & .12 \\
\hline & test & $.52 *$ & .05 & -.16 & .08 & -.02 & .36 \\
\hline
\end{tabular}


Table 1

Continued

\begin{tabular}{|c|c|c|c|c|c|c|c|}
\hline \multirow{2}{*}{ causal facter } & \multirow{2}{*}{ problem } & \multicolumn{6}{|c|}{ Factor } \\
\hline & & I & 11 & III & IV & V & IV \\
\hline \multirow[t]{5}{*}{ listening carefully } & 1 & .05 & .10 & .20 & -.05 & -.14 & $.75^{*}$ \\
\hline & 2 & $.58^{*}$ & -.11 & -.19 & .11 & -.06 & .25 \\
\hline & 3 & $.68^{*}$ & .16 & .25 & .08 & -.03 & -.11 \\
\hline & 4 & $.74^{*}$ & .15 & .01 & .06 & -.15 & -.02 \\
\hline & test & $.45 *$ & .16 & -.05 & .21 & -.40 & .22 \\
\hline \multirow[t]{5}{*}{ exercise } & 1 & .19 & -.04 & .22 & -.14 & .16 & $.64^{*}$ \\
\hline & 2 & $.68^{*}$ & -.08 & .01 & -.09 & .11 & .26 \\
\hline & 3 & $.66^{*}$ & .12 & .11 & -.08 & .14 & -.16 \\
\hline & 4 & $.67^{*}$ & -.01 & .15 & .21 & .00 & .08 \\
\hline & test & $.54^{*}$ & .08 & .05 & .11 & -.17 & .37 \\
\hline \multirow{5}{*}{$\begin{array}{l}\text { study on the day } \\
\text { before the exam. }\end{array}$} & 1 & $48^{*}$ & -.17 & -.03 & .01 & .01 & .22 \\
\hline & 2 & $.56^{*}$ &.- .18 & .10 & .12 & -.25 & .25 \\
\hline & 3 & $.59^{*}$ & .03 & -.12 & .13 & .05 & -.06 \\
\hline & 4 & $.69^{*}$ & -.16 & .04 & .05 & -.17 & .07 \\
\hline & test & $.63^{*}$ & -.16 & .08 & ..29 & -.10 & .29 \\
\hline
\end{tabular}

tribution research considers that 'ability' and 'task difficulty' are independent of each other, but the result of the factor analysis in this study showed that both had large loadings on the same factor. In an examination where a lot of students tackle the same task, it is natural for students to expect that perceived difficulty of the test problems would mean their own ability.

The third factor reflects "mood and physical condition'. The fourth factor has large loadings for 'luck' items and since students have little right to choose their own teacher in ordinary school settings, it might be lucky that their teacher taught them well. Finally the loading pattern of the fifth factor indicates that the factor can be called 'other persons" factor.

The exploratory factor analysis found five causal factors relatively general across various problems that were 'effort', 'mood', 'ability' (including 'task difficulty '), 'luck', and 'others' and one effort factor specific to problem 1 of which performance is mainly determined by student memory.

\section{Study II}

In Study II we tried to investigate the effect of students' causal attributions as major cognitive factors on expectancy/ affect, achievement-seeking behavior (or learning behavior), and their performance in a real teaching-learning situation of high-school algebra. In achievement-related situations the following general causal sequence may be hypothesized: performance $\rightarrow$ attributions $\rightarrow$ expectancy/affect $\rightarrow$ achievement-seeking behavior (learning behavior) $\rightarrow$ performance. Based on this causal sequence model the present study aimed to examine the relationships among the following variables:

1) causal attributions made for performance of mathematics test of the first semester, 2) expectancy for the next test performance, 3) satisfaction with the first test performance, 4) learning behavior of mathematics after the first test, and 5) the test performance of the next semester.

\section{Method}

Subjects and procedures. Subjects were 114 
freshmen at a senior high-school affiliated to a university. Students were asked to answer causal attributions for their test performance, their expectancy for the next test performance, and satisfaction with their test performance, when they were given back their cxamination papers with scores in mathematics class. About one month later, a questionnaire on their study behavior of learning mathematics developed by the authors was administered. Finally, the test scores of mathematics of the second semester were obtained from a teacher.

Measures. (1) Causal ascriptions for test performance. Study I found out five causal factors basically common to various test problems, which were effort, ability/task difficulty, mood, luck and other persons. For the present study, two causal ascriptions were designed for each of these five factors. The content of items for students who felt that they did well or rather well at the test are as follows: 1) effort: "I made an effort.", "I solved exercises and problems in the textbook and reference book well." 2) ability: "I have ability.", "The test problems were easy for me." 3) mood: "I felt fine at the test.", "I was in good physical condition at the time of the test." 4) luck: "I was lucky.", "The speculation turned out well." 5) other persons: "My friends taught me well.", "Other persons kindly helped me."

Items with negative expressions were used for students who felt that they did poorly or rather poorly. These items were rated on a five-point scale from 1 (not a cause) to 5 (very much a cause) and the points of two items were added to give a score of each causal factor.

(2) Expectancy. Expectancy was rated by the following procedure in accordance with the method to rate efficacy-expectancy in Bandura and Adams (1977). Ten achievement levels were cstablished as follows: "to get a score more than 10", " to get a score more than 20 ", . . and, " to get a score more than 90 ", and "to get a score of $100 "$. For each of these ten levels, students rated their perceived certainty to attain them on a eleven point scale, ranging in 10-unit intervals from 0 (impossible) to 100 (completely certain). In this study the mean score of ten rating scores for each task level was used as the expectancy score.

(3) Satisfaction. As a general affective reaction to one's own performance, satisfaction ratings were made on a 7-point scale from 1 (very much dissatisfied) to 7 (very much satisfied).

(4) Learning behavior. A newly developed questionnaire for this study was administered to inquire about students' learning behavior at home. Students rated 50 different study behaviors in terms of how often they do them on a 5-point scale from 1 (never do) to 5 (always do). Sample items of this questionnaire are shown below under categories of behavior: 1) basic learning behavior related to a curriculum: "to remember technical terms and symbols", "to read a textbook carefully and repeatedly". 2) active learning behavior related to a curriculum: "to design test problems by oneself", "to try to find out another solution". 3) general learning behavior: "to read books that a teacher recommends", "to go to museums".

\section{Result}

Causal altributions. Factor analysis based on the ten attributional ratings found five causal factors corresponding to the results of Study I. Five attribution scores were obtained by the sum of ratings of two items which constructed each factor. Accordingly attribution scores may be varied from 2 to 10 . Figure 1 shows the means of attribution scores. The tendency to attribute to effort was highest.

Expectancy. The mean score of the ten expectancy ratings gained in various performance levels was used as the expectancy score in the following analysis. The 
mean of the expectancy score was 4.92 .

Satisfaction. The mean of satisfaction was 2.2 on a 7 -point scale, so generally speaking, students seemed to be dissatisfied with their test performance. Because of this, the variable name "dissatisfaction" instead of "satisfaction " will be used in the following discussion. The score of satisfaction was inverted to get the score of dissatisfaction.

Learning behavior. Fifty items of learning behavior were analysed by principal component analysis and two factors were retained and rotated by Varimax method. The first factor had large loadings for the following items; "to remember how to use theorems", "to try to grasp the point ", "to read the textbook well ", " to solve problems in a workbook", and so on. All of them represented basic learning behavior directly related to classroom learning. The second factor showed large loadings for the following behaviors; "to read a scientific magazine or a mathematical magzine", "to visit museums", "to think of another solution ", "to solve test

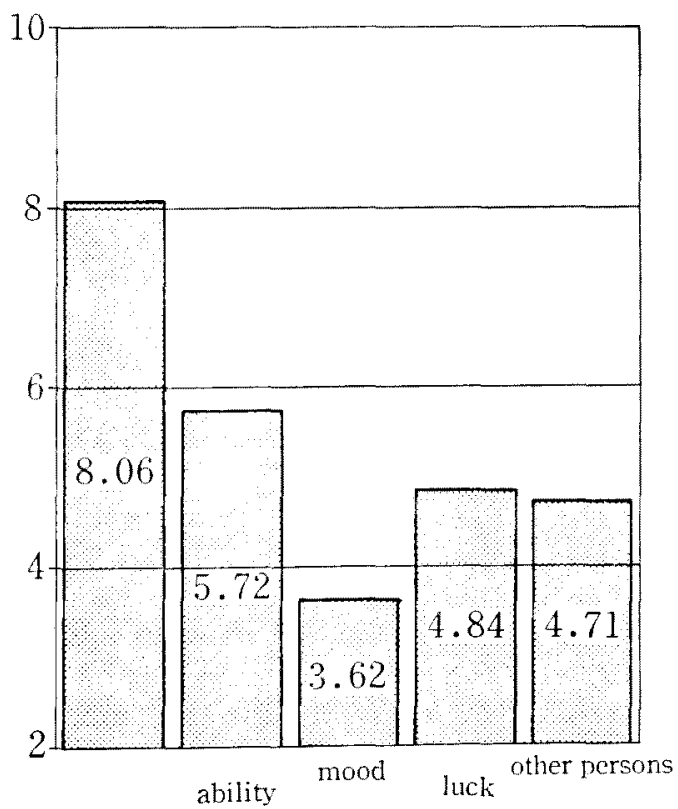

Fig. 1. Means of attributions made for the test performance. problems again ", and so on. These behaviors reflected learning which was not directly related to the mathematics class and reflected learning which expanded classroom teaching. The itcms whose loadings were greater than .40 were gathered to make two scales, Basic Learning Behavior and Expanded Learning Behavior, corresponding to two factors.

Relationships among causal attributions, expectancy/dissatisfaction, and test performances. We hypothesized a causal model composed of four steps. In the first step, mathematics performance on the first test would influence the causal attributions. Secondly, this attributional process would affect expectancy and dissatisfaction as an emotional reaction and then these two intermediate variables would produce individual differences of actual learning behaviors. Finally differences of learning behaviors would influence mathematics performance on the second test. Path analysis was performed according to this model.

Statistically significant paths $(p<.05)$ are designated with standardized partial regression coefficients in Fig. 2. One causal factor, Luck, is deleted from the dia-

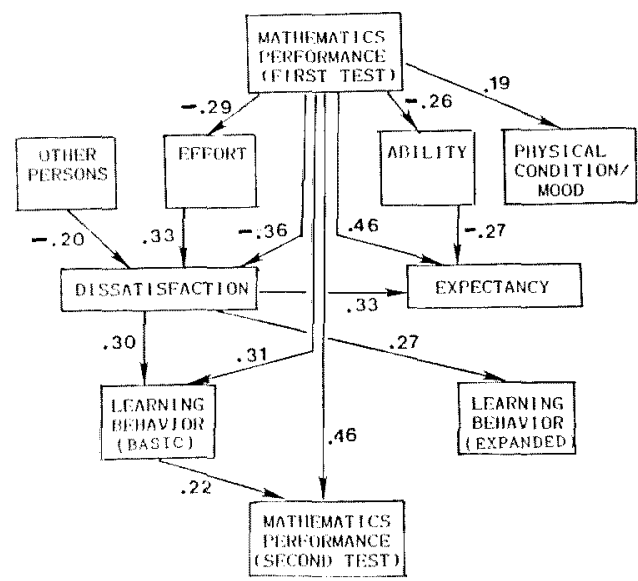

Fig. 2. Relationships among causal attributions, expectancy/dissatisfaction, and test performances. 
gram because it has no significant relation to any other variables.

Three of five causal factors had shown significant relationships to the first performance. As performance decreases, attributions to low effort and low ability tend to increase. Conversely mood and physical condition factors had a positive relationship to the first performance.

On the effect of attribution processes to expectancy, ability showed a negative significant relationship to expectancy, controlling the effect of the first test performance. Students who had a stronger attributional tendency to low ability expected that they would get lower scores in the future test. These results are consistent with previous studies.

Two factors were significant in the relationships between causal attributions and dissatisfaction. Students who have stronger attribution to low efforts express stronger dissatisfaction with their test performance. Conversely, students with stronger attribution to other persons tend to express little dissatisfaction. Further, students who were more dissatisfied with their own performance tend to expect a better performance at the next test.

Expectancy does not have any effects on learning behaviors and future performance, but dissatisfaction shows a significant positive relationship to learning behavior of both types. Fxpanded learning behavior has no clear relationship with the second performance. On the other hand, basic learning behavior which is directly related to classroom teaching influences the second test performance. Although it is naturally expected that the second test performance is correlated with the first test performance and the path between the two performances is significant, the effect of basic learning behavior on the second performance is still significant even if the effect of the first performance on the second is excluded. Accordingly, it is suggested that the difference of causal attributions influences future performance through dissatisfaction and basic learning behavior indirectly.

\section{Discussion}

In Study I we examined the structure of causal factors. And we confirmed basic factors, such as effort and ability, which have been used in much attribution research. All causal items specific to the examination situation have showed high loadings for effort factor. It is suggested that items, "I reviewed my lesson well", "I listened to my teacher carefully ", "I solved exercise problems", and so on reflect concrete behaviors of effort. But it was found that the effort items specific to problem 1 constituted an independent factor from the general effort factor. This fact suggests that effort attribution of simple memory tasks may have a somewhat different nature from the general effort attribution.

In this study 'ability' and 'task difficulty' constituted the same factor. In a specific situation such as an examination, both factors may be highly correlated. On the other hand, ' $M y$ teacher taught me well.' and 'I was lucky.' formed into the same group. From these results and from the fact that temporal effort such as "I studied hard on the day before the cxamination." was not distinguished from enduring effort in the previous studies, it should be concluded that Weiner's model which insists on the independency of three dimensions: locus of causality, stability, and controllability is inadequate in a real school setting.

The 'other persons' factor was extracted as an independent factor from other factors in this study. And this factor should be considered more carefully. This factor has been assumed to be an external factor rather than an internal one in the previous study. But one can choose appropriate persons to help oneself, and one can control other persons to some extent. Because of this, the 'other 
persons' factor may be an internal factor as well as an external one. Levenson (1974) has emphasized the discrimination of 'powerful others' factor from 'luck', and Higuchi et al. (1983) also reported that affiliative bchavior was related to achievement motivation in girls. Path analysis in Study II has showed the "other persons' factor was related to dissatisfaction and had an indirect effect on the next performance. In future research on attribution in achievement related situations, 'other persons' factor should be studied more carefully.

In Study II we tried to investigate the causal links among causal attributions as cognitive factors, learning bchavior and test performance. It is found that causal attributions had significant relationships with past performance, expectancy as perceived controllability, dissatisfaction as an affective factor. Although expectancy and dissatisfaction were strongly affected by past performance causal attributions showed significant relationships to expectancy and dissatisfaction even if the effect of past performance was excluded. This result means that causal descriptions by students are not merely reflections of past consequences (e.g. One feels 'I am smart because I had a good grade'.), but they are valid intervening variables to predict expectancy and dissatisfaction.

The negative relationship between performance and attribution to ability shown in the present study is consistent with the results of past attributional studies. On the other hand, past researchers reported inconsistent results on the relationship between performance and attribution to effort. In a series of intensive studies Dweck has asserted that effort attribution of negative events produced better performance than ability attribution. However, recent research reported negative correlation between effort attribution and performance (Covington \& Omelich, 1979; Marsh, 1984). The present study suggests that this contradiction may be explained from the point of view of the double functions of attribution. In one aspect, attribution is an interpretation of past consequences (interpretative function) and in the other aspect, attribution links to expectancy and future behavior (predictive function). In the present study effort attribution was negatively related to past performance, and this negative relationship may reflect the interpretative aspect. On the other hand the positive relation suggested by Dweck may reflect the predictive aspect. Study II showed that effort attribution had a positive relationship to dissatisfaction and then had a positive effect on learning behavior and indirectly on future performance. It is important to distinguish these two aspects of attribution.

Further the present study clearly showed that causal attributions as cognitive variables had some indirect effects on learning behavior and future performance. Though second performance had a relatively strong correlation with first performance, basic learning behavior showed a significant effect on the second performance. Consequently the second performance was indirectly affected by causal attributions. This result confirmed the hypothesis that the difference in causal attribution would affect the following learning behavior and as a result it would affect on future performance to some extent.

Considering previous studies, it was predicted that expectancy would affect learning behavior. But in the present study expectancy did not show a significant relation to learning behavior and future performance. Howcver an affective variable such as dissatisfaction played a more important role. Bandura and Cervone (1983) suggested that dissatisfaction would motivate achievement behavior for those who have high self-efficacy, and Weiner also has emphasized the importance of the affective variable as a motivator. The result of the present study is consistent with these conceptualizations. 
Further wsearch should investigate the role of affective variables in achievement motivation more thoroughly.

As the mean score of satisfaction with performance was very low, their performance in the examination was perceived as a failure by most students. Although the present study showed that dissatisfaction had a positive effect on learning behaviors and performance, many studies on learned helplessness claim that noncontingent failures may produce helplessness ( $c f$. Kambara, Kametani, \& Higuchi, 1983). Also Kambara and Higuchi (1987) reported that general perceived control showed decrease with age in Japan and corrclated with depressive feelings. From these results it is suggested that highly negative self-evaluation of students' performance which is general in Japanese educational circumstances would decrease future motivation to learn. Long-term research will be required on this issue.

The present study showed the importance of the intervening role of learning behaviors. Though basic learning behavior had a significant effect on performance, expanded learning behavior had not. In a short term study as this is, expanded learning behavior could not bring an immediate result on students' performance as it is not directly related to classroom teaching, whereas basic behavior has an immediate effect. However expanded learning behavior is related more closely to motivation of learning by oneself, and it is expected that the expanded learning behavior should be effective to performance observed over a long term. At the same time closer analysis of learning behaviors and those relationships to performance will be needed.

The fact that the effect of causal attributions was confirmed in a real teachinglearning process has important implications for education. It is expected that reconstruction of students' causal attributions would promote their learning behavior and more general achievement related behavior and also have a positive effect on their performance. We have to find ways of changing students' causal attributions and affective variables, and have to investigate the effect of these methods on learning behaviors and motivation to learn.

\section{References}

Aikawa, A., Mishima, K., \& Matsumoto, T. 1985 Effects of causal attributions on an achievement test to students: an examination of Weiner's causal attribution model of motivation. Japa nese Journal of Educational Psychology, 33, 195-204. (In Japanese with English abstract)

Bandura, A., \& $\Lambda$ dams, N. E. 1977 Analysis of self-efficacy theory of behavior change. Cognitive Therapy and Research, 1, 287-310.

Bandura, A., \& Cervone, D. 1983 Self-evaluative and self-efficacy mechanism governing the motivational effects of goal system. Journal of Personality and Social Psychology, 45, 1017-1028.

Covington, M. V., \& Omelich, C. L. 1979 Are causal attributions causal? A path analysis of the cognitive model of achievement motivation. Journal of Personality and Social Psychology, 27, 14871504.

Dweck, C. S. 1975 The role of expectation and attributions in the alleviation of learned helplessness. Journal of Personalily and Social Psychology, 31, $674-685$.

Higuchi, K., Kambara, M., \& Ohtsuka, Y. 1983 An examination of causal attribution model about academic achievement of elementary school children. Japanese Joumal of Educational Psychology, 31, 18-27. (In Japanese with English abstract) Kambara, M., \& Higuchi, K. 1987 Age changes and correlates of internal-external locus of control. Japanese Journal of Educational Psychology, 35, 177-183. (In Japanese with English abstract)

Kambara, M., Kametani, H., \& Higuchi, K. 1983 Review of the studies on learned helplessness in humans. Japanese Journal of Educational Psychology, 31, 80-95. (In Japanese with English abstract)

Levenson, H. 1974 Activism and powerful others; distinction within the concept of internal-external control. Journal of Personality Assessment, 38, 377383.

Marsh, H.W. 1984 Relations among dimensions of self-attribution, dimensions of self-concept, and academic achievements. Journal of Educational 
Psychology, 76, 1291-1308,

Ronis, D. L., Hansen, R. D., \& O'Leary, V.E. 1983 Understanding the meaning of achicvement attributions: a test of derived locus and stability scores. Journal of Personality and Social Psyclology, 44, 702-711.

Weiner, B. 1979 A theory of motivation for some classroom experiences. Journal of Educational Psychology, 71, 3-25.

Weiner, B. 1983 Some methodological pitfalls in attributional research. Journal of Educational $P_{s y}$ chology, 75, 530-543.

Weiner, B., Frieze, I., Kukla, A., Reed, L., Rest,
S., \& Rosenbaum, R. M. 1971 Perceiving the causes of success and failure. In E. E. Jones, D. E. Kanouse, H. H. Kelly, R. E. Nisbett, S. Valins \& B. Weiner (Eds.), Atribution: Pereeiving the Causes of Behavior. Morristown, N. J.: General Learning Press.

Weiner, B., Heckhausen, H., Mcycr, W., \& Cook, R. E. 1972 Causal ascriptions and achievement behavior; a conceptual analysis of effort and reanalysis of locus of control. Journal of Personality and Social Psychology, 21, 239-248.

(Received July 15, 1989; accepted Jan. 20, 1990) 